A GC

R Guragain

CL Bhusal

\section{P Sinha}

Ganesh Man Singh Memorial Academy for ENT and Head \& Neck Studies, Kathmandu, Nepal

\section{Correspondence to:}

Dr. Anita GC.

Ganesh Man Singh Bhawan

TU Teaching Hospital, Maharajgunj, Kathmandu, Nepal

E-mail: gcanita@hotmail.com

\section{OUTCOMES OF PAEDIATRIC ENT APPOINTMENT FOR SURGERY}

Objective:

To find out the average waiting period for elective surgery and turn up rate in paediatric otorhinolaryngology in the Department of GMS Memorial Academy for ENT and Head \& Neck Studies, Tribhuvan University Teaching Hospital

Material and methods:

Paediatric ENT appointment register for elective surgery and paediatric ENT surgery register were analyzed from 8th February 2009 to 9th February 2010 to see for the average waiting period for surgery, the turn up rate, reasons for non-attendandce, postpone and cancellations.

Results:

A total number of 417 children had their name in the appointment register for elective surgery. Out of them, 322 children were given date for elective surgery and 95 children were called for chance basis. Fifty-one percentage 195 of children who were dated for elective surgery had an average waiting period of 5-6 months, 182 patients didn't turn up for the surgery, 30 patients were postponed by prior information, two surgeries were cancelled at the time of operation and eight surgeries were not performed due to other reasons. Out of the 220 patients that underwent surgery, only $68(31 \%)$ patients were dated while the rest were either on chance basis or adjusted due to urgency for surgery due to various regions. The most common surgery performed in the children who were dated was unilateral myringoplasty where as adenotonsillectomy was the most common surgery in the children who were operated on chance basis.

Conclusion:

The average waiting period for elective surgery in paediatric otorhinolaryngology is quite long and the turn up rates in the elective surgery is also not high. To reduce both the parameters and to provide better services to the patients, a pre-admission assessment clinic prior to surgery and provision of an urgency categorization of the disease might be helpful.

Key words: paediatric patient, waiting period, elective surgery.

\section{INTRODUCTION:}

It is estimated that 25,000 patients visit to the Department of ENT \& Head and Neck Surgery (ENT-HNS) of Tribhuban University Teaching Hospital every year and among them 1600 (6.5\%) patients undergo surgery. Among these patients nearly $15 \%$ are the paediatric patients. In the year 2010, 3668 children visited the department of ENT-HNS and out of which 250 children underwent elective surgery. It is increasing challenge for us to manage the increasing list of patients who are planned for paediatric surgeries.

In a study of Coir, 1 it was mentioned that $15 \%$ of 731 patients had been waiting for three years for their surgery and over 350 hours of theatre time and over 3,200 in-patient bed days would be required to clear this waiting list. However, in contrary to the long waiting list, it was seen that there was significant incidence of non attenders (drop out) in the age group of less than 16 years as in the study of Hampal and Flood.2 Non attendance leads to wastage of valuable theatre time and prolongs the already lengthy waiting list times for the rest of the patients. Saskatchewan Surgical Patient Registry of Saskatchewan, America showed that in the paediatric age group, there were various waiting periods for different types of surgeries, such as maximum number of patients waited for 3-6 weeks for myringotomy, 7-12 weeks for nasoseptal reconstruction and 4-12 months for tonsillectomy with or without adenoidectomy. ${ }^{3}$

To reduce the burden of the waiting list in the paediatric age group, many countries have devised priority classification level for different surgical illnesses that would have to undergo surgery in the specified defined period of time. However, we do not have such guidelines in Nepal. It is an increasing challenge for hospitals to maintain a focus on rising demand for elective surgery in Paediatric ENT. The objectives of our study were to determine average waiting period for elective surgery in paediatric ENT patients, and their turn up rate in paediatric otorhinolaryngology.

MATERIAL AND METHODS:

It was a retrospective study carried out from 8th February 2009 to 9 th February 2010 in the unit of Paediatric Otorhinolaryngology in GMS Memorial Academy for ENT \& Head and Neck Surgery, TU Teaching Hospital. Paediatric ENT appointment register for surgery was analyzed for the duration of waiting period, number of patients who were dated for surgery, number of patients turning up for surgery on the given date and also the number of patients who were called on chance basis i.e. if electively called patients didn't turn up then the patients called on chance basis would get the opportunity to be operated, so the operating theatre time didn't go waste. Paediatric ENT surgery register was also analyzed to see the total number of surgeries performed, to see the number of dated patients that underwent surgery, to see the number of chance basis patients that underwent surgery and to see the number of patients that underwent surgery but were not noted in the pediatric ENT appointment register.

RESULTS:

We have one day in a week set for surgery for paediatrics ENT. Out of the 52 OT days in the year, we had only 48 days of OT days due to public holidays and OT cleaning day. Two hundred twenty cases had undergone various surgeries during the period. So, on an average there were 4.5 cases per day. In the period of one year, 417 patents were given dates for surgery, out of which, 322 patients were dated while 95 patients were called for chance basis. It was seen that $51 \%$ (195 patients) of the dated patients had waiting period of 5-6 months and the maximum waiting period was 9 months.

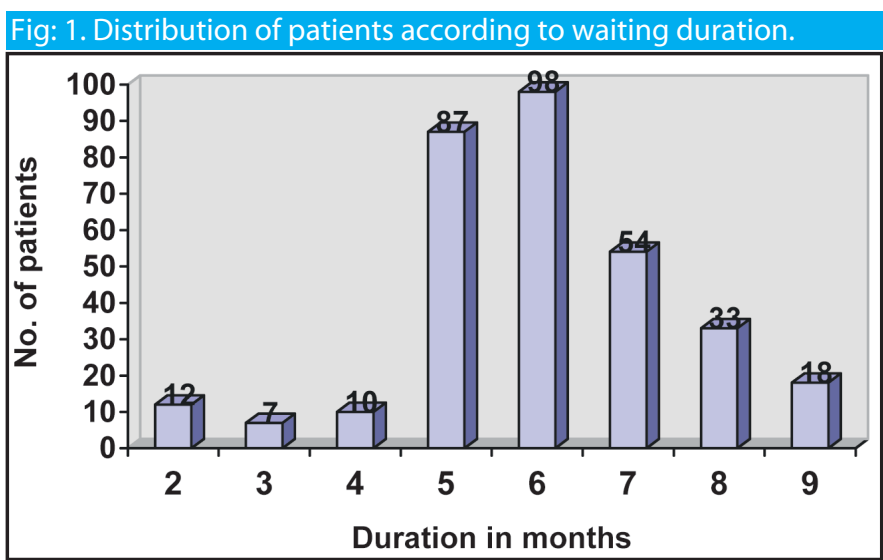

Out of the 220 patients that underwent surgery, 68 (31\%) patients were dated while the rest were either on chance basis or either not mentioned in the appointment register. Out of the 417 patients dated for surgery, 182 patients didn't turn up for the surgery, 30 patients 
were postponed, two surgeries were canceled and 8 surgeries were not performed due to other reasons. Out of 182 patients who didn't turn up for surgery, randomly 20 patients were telephoned and asked why they were unable to come on the contact date and the reasons are given in the table 1. Guardians of seven children informed us that they had been operated elsewhere as they thought that waiting period was too long. Thirty surgeries were postponed and the most common cause for postponing was active infection of the ear and viral illness. Two cases were canceled, one was due to time constraint and the other was due to anaesthetic complication during induction of anaesthesia.

\begin{tabular}{|l|c|}
\hline \multicolumn{2}{|c|}{ Table: 1. Causes for not appearing on the contact date for surgery } \\
\hline Causes & No. of patients \\
\hline Operated elsewhere & 7 \\
\hline Pre-poned & 3 \\
\hline Late for appointment & 2 \\
\hline Patient not well & 5 \\
\hline Financial reason & 1 \\
\hline Improving & 1 \\
\hline Lost papers & 1 \\
\hline Table: 2 . Causes for postponement of surgery \\
\hline Causes & No. of patients \\
\hline Active infection of the ear & 10 \\
\hline Fever & 6 \\
\hline Incomplete investigations & 1 \\
\hline Opinion for plastic surgery & 1 \\
\hline Cause not noted & 12 \\
\hline
\end{tabular}

The most common surgery performed in the children who were dated was unilateral myringoplasty and adenotonsillectomy was the most common surgery in the children who were operated on chance basis.

\section{DISCUSSION:}

In our study, only $31 \%$ of the children who were given appointment for surgery underwent surgery on the given date. One hundred eighty two children didn't turn up for surgery, whereas 30 patients were postponed, two surgeries were canceled and 8 surgeries were not performed due to other reasons. Hampal and Flood2 found that $14.6 \%$ of operations were canceled due to non-attendance of the patient. It has also been reported that the commonest cause of patient self cancellation is upper respiratory tract infection, which is commoner in winter and is considered to be a contraindication for ENT surgery. 4 In our study, the common cause of cancellation was due to active infection in the chronic otitis media, mucosal type followed by viral fever. Those patients on longer waiting lists were less likely to attend than those on shorter waiting lists. 5 In contrast, those patients with serious diseases such as cholesteatoma were less likely to default than those with relatively more trivial disease such as those listed for septal surgery. 5 The underlying reason may partly be due to the severity of the symptoms experienced by the patient, and partly to the nature of the advice offered by the medical officer regarding complications resulting from delay of the treatment. 5 So, categorization of the disease into grades of severity and giving dates accordingly might be helpful to relieve the symptoms in a child with more severe disease and also to allay the anxiety of the parents.

The advantages of the pre-admission clinic have been discussed at length in other studies.4-6 Pre-admisision clinic at our setup might be helpful for recognizing the patients who might get canceled due to infections or patients who won't be turning up for surgeries because they have been operated somewhere else, so that we can adjust other children who are in the waiting list. In a study of Woolford, nineteen $(27 \%)$ of the 70 children who completed the study were in the waiting list no longer warranted surgery and were removed from the waiting list and they concluded that those children who had been on the waiting list for a long period of time should be reassessed prior to the planned tonsillectomy to see if surgery is still indicated.7

As we also call children for surgery on chance basis that is when the parents think that the waiting period is long they can come sooner but will get a chance for the surgery only if the elective patients do not turn up for the surgery. This system has been helpful to us as the theatre time does not go in waste, if the elective patients do not turn up. However, the surgery appointment register could be filled in more detail regarding the patients on chance basis, causes of postponing, cancellations, not turning up and if operated on earlier date which would be helpful for better and further studies.

Finally the recommendations of this audit are: 1 . Surgery appointment book to be filled in detail and correctly. 2. Urgency Categorization of the disease. 3. Pre-admission assessment Clinic

\section{CONCLUSION:}

As a tertiary centre of the country there is much load in the elective surgery list in the Paediatric Otorhinolaryngology unit of TU Teaching Hospital. The waiting period is quite long and the turnover is not as expected. There are many factors which may be responsible and some modifications such as urgency categorization of the disease and pre-admission assessment clinic might be helpful to achieve a better service to the patients.

REFERENCES:

1. Coid DR. Managing the Fife ENT (ear, nose and throat) waiting list: the 1989 review of problems. Health Serv Manage ResÊ1990; 3: 82-6.

2. Hampal S, Flood LM. Why patients fail to attend for ENT operations:A one year prospective audit. Clin Otolaryngol 1991; 17: 218-22.

3. Saskatchewan Surgical Patient Registry. Saskatchewan Surgical Care Network, Saskatchewan Health, Government of Saskatchewan; 2009.

4. Dingle AF, Bingham B, Krishnan R, Gibb JG, Thompson CJ, Flood.Pre admission assessment clinics: an answer to nonattendance for ENT operations. Clin Otolaryngol 1993; 18: 415-8.

5. Robin PE. Pre-admission clinics. Br Med J 1991; 302: 532.

6. Grover S, Gagnon G, Flegel KM, Hoey JR. Improving appointmentkeeping by patients new to a hospital clinic with telephone or mailed reminders. Can Med Assoc J 1983; 129: 1101-3.

7. T.J. Woolford, A. Ahmed,ÊD.J. Willatt,ÊM.P. Rothera. Spontaneous resolution of tonsillitis in children on the waiting list for tonsillectomy. Clin Otol All Sci 2000; 25: 428-30. 